\title{
МЕТОДЫ ОЦЕНКИ КОРПОРАТИВНОЙ КУЛЬТУРЫ
}

ОРГАНИЗАЦИИ

\section{METHODS FOR EVALUATING THE CORPORATE CULTURE OF AN ORGANIZATION}

\section{T. Kurbatskaya \\ N. Vysotskaya \\ N. Kurbatsky \\ A. Gamirullina}

Summary: It is impossible to effectively manage a modern organization without taking into account the peculiarities of its corporate culture. Corporate culture is the rules of behavior recognized in a particular organization (values; social, communicative and moral norms; rituals; corporate identity) and management rules (organizational structure, communications, personnel policy). The corporate culture serves as the foundation for interaction between employees in the process of achieving the established goals of the organization, helping management to fulfill the mission of the organization. The influence of corporate culture covers the entire organization and is an essential element of its activities, which forms its unique image. A positive effect from the influence of corporate culture is achieved only when it is supported by the majority of employees, not only in words, but also in deeds. That is why the formation of the correct corporate culture of the organization is necessary for its functioning and correct development.

Keywords: diagnostics, corporation, corporate culture, organization, efficiency, methods, methods for assessing corporate culture, research, characteristics of methods for diagnosing the corporate culture of an organization.
$\mathrm{B}$ ходе поиска и анализа литературы [Курбацкая Т.Б., Мявлина Н.Ж., 2020] выяснилось, что для коррекции корпоративной культуры можно использовать следующие диагностические методики:

1. опросник Д. Денисона «Оценка корпоративной культуры и развития лидерства»;

2. методику определения типа корпоративной культуры (по Т.Ю. Базарову);

3. методику выявления качества корпоративной культуры предложенной компанией Nationwide Brokerage Solutions (NBS);

4. методику Р. Гэлэгера;

5. методику «Target Culture Modeling - C-Sort».

Краткая характеристика данных методов:
Курбачкая Татьяна Борисовна

К.псх.н., дочент, Московский университет им. С.Ю. Buтmе; доцент, Российский университет транспорта alterego123@yandex.ru

Высочкая Наталия Владимировна Д.э.н., профессор, Российский университет транспорта vyssotsk@mail.ru

Курбацкий Никита Владимирович Московский университет им. С.Ю. Bumme Гамируллина Анастасия Сергеевна Российский университет транспорта a.gamirullina@yandex.ru

Аннотация: Управление современной организацией невозможно эффективно осуществлять без учета особенностей ее корпоративной культуры. Корпоративная культура - это признаваемые в конкретной организации правила поведения (ценности; социальные, коммуникативные и моральные нормы; ритуалы; фирменный стиль) и правила управления (организационная структура, коммуникации, кадровая политика). Корпоративная культура служит фундаментом взаимодействия между работниками в процессе достижения поставленных целей организации, помогая руководству выполнять миссию организации. Влияние корпоративной культуры охватывает всю организацию и является важнейшим элементом ее деятельности, который формирует ее неповторимый образ. Положительный эффект от влияния корпоративной культуры достигается лишь в том случае, когда она поддерживается большинством работников не только на словах, но и на деле. Именно поэтому, формирование правильной корпоративной культуры организации необходимо для ее функционирования и правильного развития.

Ключевые слова: диагностика, корпорация, корпоративная культура, организация, эффективность, методы, методика оценки корпоративной культуры, исследование, характеристика методов диагностики корпоративной культуры организации.

\section{1. Опросник организашионной культуры $\Delta . \Delta$ энисона «Ошенка корпоративной культуры и развития лихерства»}

Данная модель и анкета организационной культуры появилась в результате 15 лет исследований доктора Дэниэля Дэнисона - профессора организационного развития в IMD, Международном Институте Развития Управления в Лозанне, Швейцария. Модель легла в основу двух диагностических исследований организационной культуры и развития лидерства, - проведенных доктором Дэниэлем Дэнисоном и Вильямом Нилом [Курбацкая Т.Б., Мявлина Н.Ж., 2020]. Результаты этих обследований сейчас используются более чем в 1200 организациях по всему миру. Дэнисон изучал корреляцию между определенными чертами организационной культуры и организационной эффективностью. Рассматриваемые черты 
культуры: вовлеченность, последовательность (постоянство, согласованность, логичность), приспособляемость (адаптация) и миссия (рис.1).

Параметр «Способность к адаптации» можно оценить с помощью индекса способности к изменениям, индекса внимания к клиентам, индекса обучаемости организации.

Параметр «Миссия» - с помощью индекса стратегического направления и намерения, индекса целей и задач, индекса видения.

Параметр «Согласованность» включает в себя индекс координации и интеграции, индекс способности к консенсусу, индекс вовлеченности в ценности.

Параметр «Вовлеченность» оценивается с помощью индекса предоставления полномочий, индекса возможности развития, индекса ориентации на работу в команде.

\section{2. Методика выявления типа корпоративной культуры (автор Т.Ю. Базаров)}

Методика разработана профессором Т.Ю. Базаровым и предназначена для выявления типа организационной культуры [Базаров Т.Ю., 2014]. Среди исследуемых параметров - векторы направления, задаваемые руководством; особенности управления персоналом; особенности потребностей и мотивации персонала; особенности управления конфликтами; коммуникационного менед- жмента; специфика принятия управленческих решений.

\section{3. Методика выявления качества корпоративной культуры (NBS)}

Данная методика позволяет получить данные об отношении к изменениям в организации, особенностях командообразования, использования стандартных алгоритмов работы, об отношении к инициативе и новаторству персонала, оценке труда [Курбацкая Т.Б., Мявлина Н.Ж., 2020]. Также можно получить информацию об особенностях обучения персонала, отношению к ответственности за выполненную деятельность, адекватности распределения ресурсов, уровне коммуникативного менеджмента, оценке организационной культуры со стороны руководства и направленной на достижение высоких показателей индекса «счастья» и максимальное вовлечение сотрудников рабочий процесс.

\section{4. Опросник Р. Гэлэгера по оченке бизнес-культуры компании}

Существует множество методик оценки любого бизнеса или произ-водства с финансовой точки зрения [Гэлэгер Р, 2006]. Также имеются эффективные методики для большинства управленческих аспектов, от производилтельности труда до торгового оборота. Но бизнес-культуру труднее описать цифрами, даже если она играет важнейшую роль в успехах по всем прочим показателям. Однако можно заметить некоторые ключевые факторы, чтобы получить полную картину существующей бизнес-культуры любой организации. Опрос-

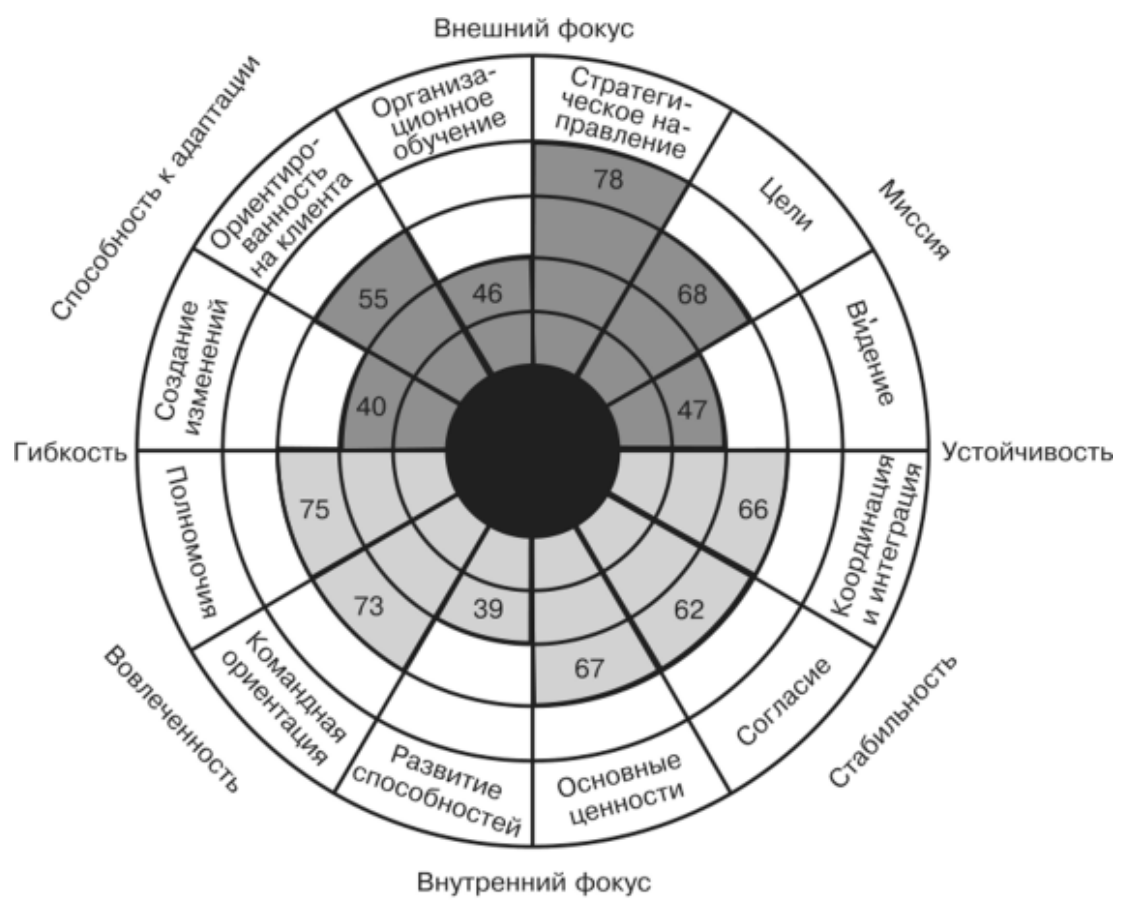

Рис. 1. Параметры корпоративной культуры по Д. Дэнисону 
ник Р. Гэлэгера позволяет с другого ракурса взглянуть на сильные стороны культуры компании. В каждом пункте опросника были утверждения, представляющие собой разные, но равноценные по значимости точки зрения на ценности компании. Следовало выбрать то утверждение, которое более точно описывает рабочую обстановку организации, и отметить подходящий ответ. Исследуемые характеристики: превосходство на уровне операций, позитивность рабочей обстановки, особенности построения команд, управления ростом и изменениями, особенности обслуживания клиентов, наличия любви к работе.

\section{5. Методика К. Камерона и Р. Куинна по оченке эффективности корпоративной культуры в организашии OCAl (Organization Culture Appreciation Instrument)}

Одной из методик диагностики и изменения корпоративной культуры является методика ОСAI (Organization Culture Appreciation Instrument). Данная методика, разработанная К. Камероном и Р. Куинном [Кемерон К., Куинн Р., 2001], позволяет обработкой специальных анкет определить количественные вклады базовых организационных культур в исследуемую культуру. Измерение конкурирующих ценностей в модели производится с помощью «шкалированных» вопросников. Оцениваются пять параметров культуры на их настоящем и желаемом уровне: важнейшие характеристики организации, стиль лидерства и руководства, управление наемными работниками, сущность организации, стратегическая направленность. В анкете параметр «А» соответствует клановой оргкультуре, «B»- адхократической, «C»- рыночной, «D» - иерархической. По методике OCAI находятся усредненные количественные вклады a, b, c, d базовых типов организационных культур и откладываются на биссектрисах соответствующих квадрантов (рис.1). Сумма а + $\mathrm{b}+\mathrm{c}+\mathrm{d}=$ е должна быть постоянной, что важно при сравнении разных профилей (четырехугольник $\mathrm{ABCD}$ ) и наиболее естественно полагать е $=100$, так как тогда a, b, c, d выражают процентные вклады базовых типов организационных культур в исследуемую культуру. Преимущества методики OCAI: во-первых, общая модель описывает ценности культуры организации в связи с каждым отдельным подходом к определению эффективности и сопоставляет перспективу одного подхода со всеми другими; во-вторых, она позволяет классифицировать организации по признаку принадлежности к тому или иному типу культуры и определить силу данной культуры; в-третьих, использование графических профилей может служить эффективным инструментом корпоративной диагностики. На основе анализа площадей наибольшего различия профилей существующей и желательной культуры можно наметить пути ее изменения и улучшения. Сравнение диаграмм различных параметров для одной и той же культуры или общих профилей для разных подразделений позволяют сделать вывод о культурной согласованности или несогласованности компании. Равновесное состояние различных аспектов культуры в различных подразделениях ведет к росту сплоченности компании и созданию благоприятного социального климата для принятия управленческих решений. Также с целью диагностики существующего уровня корпоративной культуры целесообразно провести оценку уровня функционального построения системы управления формированием и развитием корпоративной культуры. Если процесс формирования и развития корпоративной культуры является заново проектируемым, уровень функционального построения корпоративной культуры должен быть оценен в первую очередь, так как на основании полученного результата можно судить о достаточности уровня элементного обеспечения и правильности организационного построения механизма формирования и развития культуры фирмы. Оценка уровня функционального построения корпоративной культуры производится на основании сопоставления тех функций-задач, которые решаются фактически в данной организации, и тех, эталонных, которые должна решать корпоративная культура [Кемерон К., Куинн Р., 2001].

Таким образом, корпоративная культура - это признаваемые в конкретной организации правила поведения (ценности; социальные, коммуникативные и моральные нормы; ритуалы; фирменный стиль) и правила управления (организационная структура, коммуникации, кадровая политика). Формированием корпоративной культуры занимается менеджер, входящий в структуру одного из отделов организации. Данный отдел взаимодействует с сотрудниками организации, разрабатывает и внедряет системы обучения, адаптации, мотивации, проводит опросы и занимается вопросами стиля и символики организации. Формирование корпоративной культуры опирается на мнение собственника организации, который определяет ее стратегию, базовые ценности и миссию. Для выполнения этих целей руководство организации может привлечь также специалистов на основе системы аутсорсинга. В настоящее время известны четыре типа корпоративной культуры: бюрократическая, предпринимательская, органическая и партисипативная. Формирование корпоративной культуры включает два этапа: этап формализации, где внедряются регламенты и процедуры и этап координации, где происходит усовершенствование, видоизменение корпоративной культуры. Современная корпоративная культура включает в себя утвержденную систему лидерства, систему коммуникаций, сложившиеся стили решения конфликтных ситуаций, действующую символику (запреты, ограничения, лозунги и ритуалы), статус каждого человека в компании. Под деформацией корпоративной культуры мы подразумеваем изменения в ней и ее структуре. Особенностями Европейской корпоративной культуры являются: внедрение основные европейских принципов корпоративного управления (принципы ОЭСР), которые 
становятся основой гарантий для обеспечения защиты прав и законных интересов акционеров и инвесторов. В Европейских организациях предусмотрена корпоративная адаптация новых сотрудников; размещение ценностей корпоративной культуры, правил и лозунгов организации на различных носителях; встречи, выступления перед персоналом, во время которых декларируются корпоративные ценности, правила и цели. К особенности Российской корпоративной культуры можно отнести объединение сотрудников в группы. В Российской модели корпоративной культуры можно наблюдать опору на личные связи и протекцию, что указывает на неформальность отношений. Таким образом, корпоративная культура в Российских организациях подразумевает наличие корпоративного духа, латентных правил, более характерных для азиатских культур. Часто в организациях не предусмотрена корпоративная адаптация новых сотрудников. В ходе анализа были выявлены следующие деформации в корпоративной культуре: формирование культуры на неформальном принципе, что ведет к размыванию основ корпоративной культуры; повышение дистанции между начальством и сотрудниками, что ведет к недовольству и расслоению в среде сотрудников, а также к моббингу. Для эффективной коррекции корпоративной культуры необходимо сделать предварительную диагностику параметров, выявить тип корпоративной культуры, ее специфические качества, а также факторы, которые требуют корректировки. В ходе поиска и анализа материала выяснилось, что для коррекции корпоративной культуры можно использовать следующие диагностические методики: методику «Target Culture Modeling - C-Sort» (моделирование целевой культуры); методику Р. Гэлэгера [Гэлэгер Р, 2006] методику определения типа корпоративной культуры (по Т.Ю. Базарову) [Базаров Т.Ю., 2014]; опросник Д. Денисона «Оценка корпоративной культуры и развития лидерства»; методику выявления качества корпоративной культуры компании (Nationwide Brokerage Solutions (NBS)).

\section{ЛИТЕРАТУРА}

1. Базаров Т.Ю. Психология управления. Теория и практика. Учебник для бакалавров. Издательство Юрайт. 2014, 381с.

2. Демин Д.В. Корпоративная культура. Десять самых распространенных заблуждений. Альпина Паблишер. 2016, 154 с.

3. Курбацкая Т.Б., Мявлина Н.Ж. Корпоративная культура. Методы диагностики. Корпоративное управление. Саарброюкен, Лап Ламберт Академик Паблишинг. 2020. - 230с.

4. Гэлэгер Р. Душа организации. Добрая книга. 2006. 352 с.

5. Деминг Э. Выход из кризиса. Новая парадигма управления людьми, системами и процессами. Альпина Паблишер. 2016, 400 c.

6. Кемерон К., Куинн Р. Диагностика и изменение организационной культуры. Перевод с английского под редакцией И.В. Андреевой. СПб Питер. 2001. $320 \mathrm{c}$. 